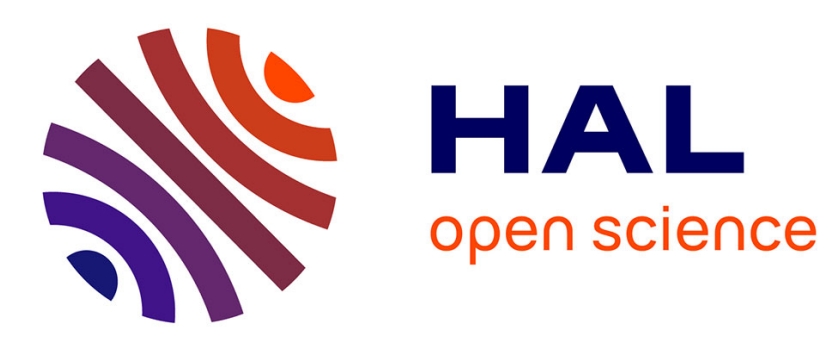

\title{
Design and Experimental Validation of a Robust Control Method for a Hybrid Fuel Cell Power Generation System
}

David Hernández-Torres, Delphine Riu, Olivier Sename

\section{To cite this version:}

David Hernández-Torres, Delphine Riu, Olivier Sename. Design and Experimental Validation of a Robust Control Method for a Hybrid Fuel Cell Power Generation System. ECCE 2010 - 2nd IEEE Energy Conversion Congress and Exposition, Sep 2010, Atlanta, Georgie, United States. pp.4482-4489. hal-00520117

\section{HAL Id: hal-00520117 \\ https://hal.science/hal-00520117}

Submitted on 22 Sep 2010

HAL is a multi-disciplinary open access archive for the deposit and dissemination of scientific research documents, whether they are published or not. The documents may come from teaching and research institutions in France or abroad, or from public or private research centers.
L'archive ouverte pluridisciplinaire HAL, est destinée au dépôt et à la diffusion de documents scientifiques de niveau recherche, publiés ou non, émanant des établissements d'enseignement et de recherche français ou étrangers, des laboratoires publics ou privés. 


\section{Design and Experimental Validation of a Robust Control Method for a Hybrid Fuel Cell Power Generation System}

\author{
David Hernández-Torres, Delphine Riu \\ Grenoble Electrical \\ Engineering Laboratory \\ 38400 Saint-Martin-D'Hères, France \\ Email: David.Hernandez,Delphine.Riu@g2elab.grenoble-inp.fr
}

\author{
Olivier Sename \\ GIPSA-Lab \\ Department of Control Systems \\ 38400 Saint-Martin-D'Hères, France \\ Email: Olivier.Sename@gipsa-lab.grenoble-inp.fr
}

\begin{abstract}
In this article a robust control methodology is proposed for an hybrid power generation structure composed by a Fuel Cell and a Super-capacitor. The control strategy and the desired performances are written as inequality constraints so they can be solved using Linear Matrix Inequalities methods. Using this method a multivariable PI control with $\mathcal{H}_{\infty}$ performance is computed, which is used to control the power converters associated with the Fuel Cell and the Super-capacitor respectively. The control performance in time and frequency domain is analyzed, with special interest in the control robust performance. The robust controller is implemented on a real-time test-bench with a Fuel Cell emulator. Results show the efficiency of the proposed methodology.
\end{abstract}

Index Terms-Robust Control, Linear Matrix Inequalities, Fuel Cells, Hybrid Power Generation.

\section{INTRODUCTION}

Fuel cells are expected to enter the market within a few years, providing a possible clean energy source for the future. High efficiency and low emissions are its main advantages. Different applications are proposed, including its use for transport propulsion or as a distributed power generation device. A Fuel Cell (FC) is an electrochemical device able to transform the chemical energy into the form of electrical energy using a pair of electrodes, an electrolyte and a catalyst. FC's are attractive because they are efficient, flexible in the modular structure they can adopt and environmentally friendly with practically no emissions (hydrogen is consumed and water plus electricity and heat are produced). Some drawbacks however include: cost, reliability, durability and the inability to efficiently produce, transport and distribute the fuel (hydrogen) [1], [2], [3].

Power generation systems based on FC's are expected to play a more important role in the future of Distributed Generation (DG) applications [2]. FC's operating as DG can be connected to the utility grid or can be operated as a stand-alone power supply system in a remote area [4]. Transport propulsion is however considered as a very important application for the FC, specially the PEM technology [5], [6]. In any case, energy quality constraints to be respected are commonly fixed by norms. These systems should also be able to adapt to fast changes in load or in the operating conditions. Within this context, appropriate control-oriented modeling and the control strategy itself are critical issues. To achieve this, a design methodology that allows to compute multivariable PI controllers, is proposed in this paper, as PI controllers are easily implemented in industrial applications. The methodology will focus on the control of DC/DC boost power converters associated to the hybrid source, however the proposed strategy is also valid for other possible conversion stages as DC/AC conversion through an inverter. For the design of multivariable PI controllers that takes into account certain robustness performance criteria, the use of Static Output Feedback (SOF) and Linear Matrix Inequalities (LMI) methods are proposed, as in [7]. This paper enhances some of the preliminary results presented in [7]. In particular, a new control structure is proposed (using a different measurement selection) that improves the closed loop performances. Furthermore, the robust controllers are validated using a real-time implementation test-bench of the hybrid generation system, this emphasize the interest of the proposed control methodology. In the test-bench, a programmable DC source is used to emulate the real FC dynamic. One of the main interest of the proposed approach relies on the design of PI controllers in the $\mathcal{H}_{\infty}$ framework, this means that systematic methodology is provided to the control engineer.

The proposed methodology for robust multivariable control design is presented is the following section. The control strategy used to compute multivariable PI controllers with $\mathcal{H}_{\infty}$ performance using an iterative LMI method is described afterward. Then, the hybrid FC/Super-capacitor system model is introduced. Finally simulation and experimental results are presented before concluding this work.

\section{STUdied System}

\section{A. System Structure}

The FC is often hybridized with an auxiliary source. This auxiliary source should be capable of supply sufficient instant power to guarantee normal operation in the presence of important energy transients without any deterioration of the 
FC. The technology behind high-current super-capacitors has been designed for this purpose. The studied system is then composed by a hybrid FC/Super-capacitor power generator. The two sources and their respective boost converters are connected in parallel and a DC filter connects the output with the supplied DC load. The energy sources are modeled according to their electrical dynamic equivalent circuit. The model used for the FC is a dynamic model that takes into account the so-called double layer dynamic effect phenomena in the cells anode and cathode [8], see Figure 1. The supercapacitor is modeled using a classical R-C model [9]. The equivalent model of the complete system is shown in Figure 2.

The system average non-linear equations are given by:

$$
\begin{gathered}
\frac{d V_{C_{c}}}{d t}=\frac{1}{C_{c}}\left[I_{f c}-\frac{V_{C c}}{R_{t c}}\right], \frac{d V_{C_{a}}}{d t}=\frac{1}{C_{a}}\left[I_{f c}-\frac{V_{C a}}{R_{t a}}\right] \\
\frac{d I_{f c}}{d t}=\frac{1}{L_{f c}}\left[E_{0}-V_{C_{a}}-V_{C_{c}}-R_{m} I_{f c}-\left(1-\alpha_{f c}\right) V_{C}\right] \\
\frac{d I_{s c}}{d t}=\frac{1}{L_{s c}}\left[V_{s c}-R_{s c} I_{s c}-\left(1-\alpha_{s c}\right) V_{C}\right], \frac{d V_{s c}}{d t}=\frac{1}{C_{s c}} I_{s c} \\
\frac{d V_{C}}{d t}=\frac{1}{C}\left[\left(1-\alpha_{f c}\right) I_{f c}+\left(1-\alpha_{s c}\right) I_{s c}-\frac{V_{C}}{R_{l o a d}}\right]
\end{gathered}
$$

State variables are: $V_{C_{c}}$ the double layer capacitor in the FC cathode, $V_{C_{a}}$ the double layer capacitor in the FC anode, $I_{f c}$ the FC output current, $I_{s c}$ the super-capacitor output current, $V_{s c}$ the super-capacitor voltage and $V_{C}$ the output filter capacitor voltage. The inputs to the system are $\alpha_{f c}$ and $\alpha_{s c}$, the average values of $u_{f c}$ and $u_{s c}$, the switching functions of the FC and super-capacitor power converters respectively. System data and parameters are taken from [8], for a $1 \mathrm{~kW}$ hybrid FC/Super-capacitor system at $24 \mathrm{~V}$ rated output voltage.

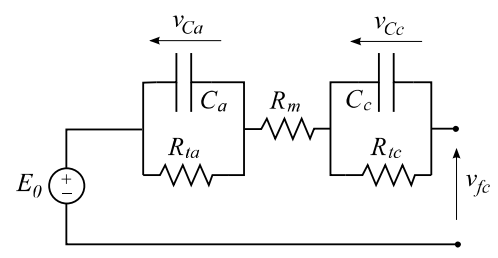

Fig. 1. Fuel Cell dynamic model.

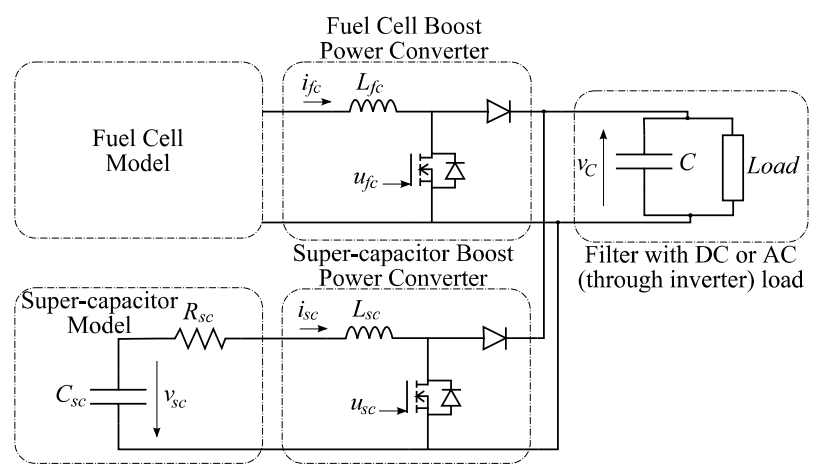

Fig. 2. Equivalent model of the complete studied system.

\section{B. Experimental Setup}

The test-bench used for validation is presented in Figure 3.

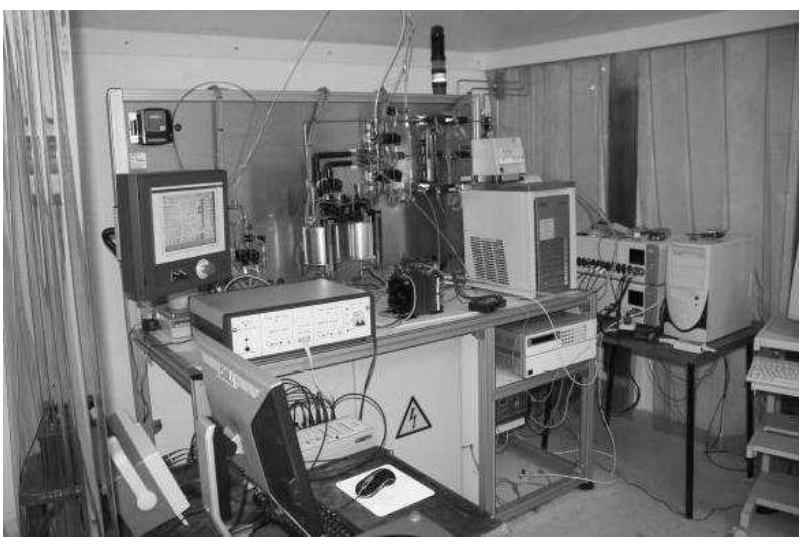

Fig. 3. Experimental setup used for validation

The test-bench is composed by a $1 \mathrm{~kW}$ Paxitech ${ }^{\circledR}$ PEM Fuel Cell and a $58 \mathrm{~F}$ Maxwell ${ }^{\complement}$ super-capacitor. The two sources are interfaced by two identical double boost DC/DC power converters. The power converters were designed however for a $500 \mathrm{~W}$ nominal power and a $24 \mathrm{~V}$ rated DC bus output voltage. The SC converter is not reversible, this means that the SC recharge from FC current is assured by a third converter, a flyback converter. The flyback however, is controlled independently from the boost converters. Under normal loading conditions, at approximately $475 \mathrm{~W}$, the flyback converter will drawn $0.4 \mathrm{~A}$ to keep the SC charge at a nominal voltage of $14.5 \mathrm{~V}$ in the SC. A small auxiliary $12 \mathrm{~V}$ battery is used to power the control boards for the boost converters, generating the necessary PWM signals. The PWM is fixed at $50 \mathrm{kHz}$. A DS1104 dSPACE $^{\complement}$ real-time control board is used to capture the system currents and voltage and to send the $0-5 \mathrm{~V}$ control signal for the PWM (duty cycle). The general layout of the test-bench is presented in Figure 4.

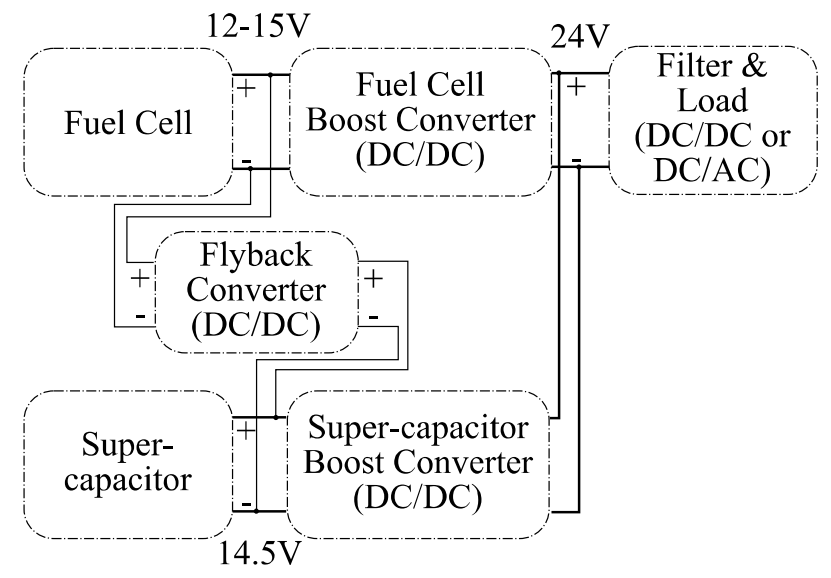

Fig. 4. Experimental setup converter configuration. 


\section{Classic Control Strategy}

Several classic control strategies for this type of system can be found in the literature. Given the known stability problems with the boost converter, most of these strategies are based on multi-loop control, see [10]. Following this approach, the hybrid system control strategy proposed in [11] is used. In this approach the FC current is controlled by means of the FC boost converter control. The output DC bus voltage control is assured by the SC boost converter control. A second stabilizing current loop is used however for the SC boost control. This strategy is presented in Figure 5.

The PI controllers are in the form $K_{p}\left(1+K_{i} / s\right)$. Classic pole compensation is used to compute the classic PI parameters. The desired second-order dynamic is defined by the damping ratio $\zeta$ and the undamped natural frequency $\omega_{n}$.

For the FC current loop PI controller $\left(K_{F C}(s)\right)$, the desired second order parameters are computed to obtain a stabilization time of approximately $t_{s}=5 \mathrm{msec}$. The SC voltage loop PI controller $\left(K_{S C_{1}}(s)\right)$ is computed for fixed $\zeta_{v}=1$ and $\omega_{n_{v}}=100 \mathrm{read} / \mathrm{sec}$. The SC current loop PI controller $\left(K_{S C_{2}}(s)\right)$ is chosen one decade faster than the voltage loop, at $\omega_{n_{i}}=1000 \mathrm{rad} / \mathrm{sec}$.

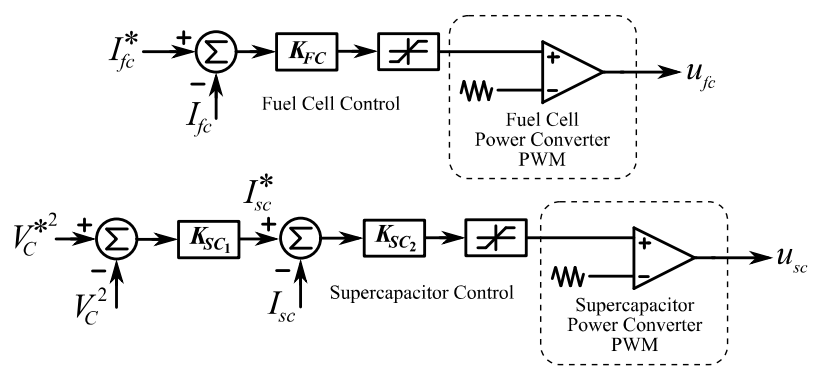

Fig. 5. Classic control strategy considered.

\section{Proposed Methodology}

Electrical equations of power converters from the real system can be described using average modeling [12]. Linearizing these equations a linear state space model could be obtained. The system validation could be achieved using the topological model or real system tests. Using a mixed sensitivity approach, performance and robustness specifications are introduced using weighting functions over particular transfer functions of the system [13]. An extended model including these weighting functions is then obtained, where uncertainties models could be introduced to consider parametric uncertainties or unmodeled dynamics for the control synthesis. The system with the desired performances are written as inequalities constraints so they can be solved using LMI's. Iterative LMI's algorithms (iLMI) has been proposed in the automatic control literature with special interest on the SOF problem formulation. In this paper the algorithm developed by [14], an improved iLMI for SOF, is used for PI controllers. A final multivariable controller is obtained until all desired specifications are satisfied. For

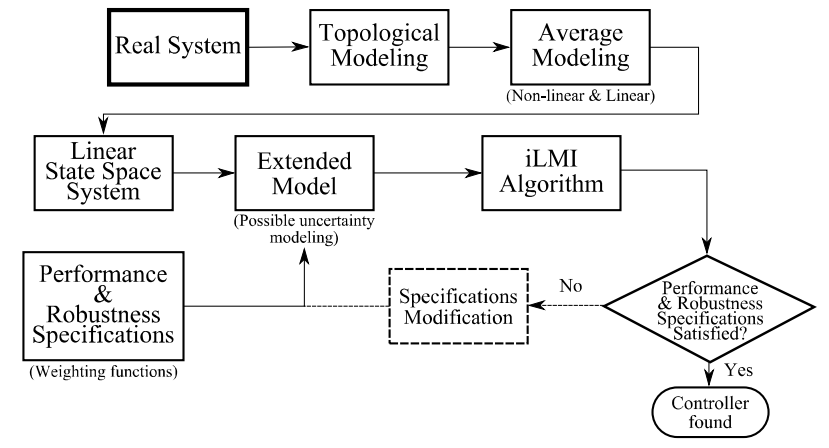

Fig. 6. Proposed methodology.

control validation, tests using the average or topological models are convenient. Implementation on the real system is the final step. The proposed methodology is resumed in Figure 6.

As shown in the literature, robustness could finally be related to several physical meaningful parameters, as the system physical mass or “jam”for example [15]. Results obtained using the proposed methodology could then lead to a complete design strategy that includes objectives as system mass optimization, critical for on-board transport applications for example.

\section{Robust Control Strategy}

The proposed control strategy is based on solving the LMI's constraints of the system using the iterative algorithm proposed in [14]. For this, the system is written using the SOF form. The problem formulation of a PID controller into the SOF form is proposed in [16]. A simplified version for a PI controller is used in this paper. The general control configuration is shown in Figure 7. The linear state space equations of this system are:

$$
\begin{gathered}
\dot{x}=A x(t)+B_{1} \omega(t)+B_{2} u(t) \\
z(t)=C_{1} x(t)+D_{11} \omega(t)+D_{12} u(t) \\
y(t)=C_{2} x(t)+D_{21} \omega(t)
\end{gathered}
$$

with $x(t) \in \mathbb{R}^{n}$ the state variables, $\omega(t) \in \mathbb{R}^{r}$ the external input, $u(t) \in \mathbb{R}^{m}$ the control input, $z(t) \in \mathbb{R}^{q}$ is the controlled output and $y(t) \in \mathbb{R}^{p}$ the measured output.

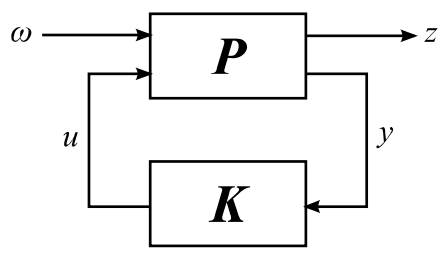

Fig. 7. General Control Configuration.

For a multivariable PI controller, $u$ is given by:

$$
u(t)=F_{1} y(t)+F_{2} \int_{0}^{t} y(\theta) d \theta
$$


For this system (2), the PI controller is rewritten as a SOF control law to obtain a new system representation. Then this SOF controller is solved with the proposed methodology. The controller $F \in \mathbb{R}^{m \times p}$ is such that the closed loop of the system satisfies certain desired performances. To impose a $\mathcal{H}_{\infty}$ performance, the controller in (3) should satisfy a closed loop $\left(T_{z \omega}\right)$ constraint of the form: $\left\|T_{z \omega}(s)\right\|\langle\gamma$ for $\gamma>0$. The $\mathcal{H}_{\infty}$ control problem of system (2)-(3) is given by the following LMI:

$$
\left[\begin{array}{ccc}
P A_{c l}+A_{c l}^{T} P & P B_{c l} & C_{c l}^{T} \\
B_{c l}^{T} & -\gamma I & D_{c l}^{T} \\
C_{c l} & D_{c l} & -\gamma I
\end{array}\right] \prec 0
$$

with: $A_{c l}=A+B_{2} F C_{2}, B_{c l}=B_{1}+B_{2} F D_{21}, C_{c l}=C_{1}+$ $D_{12} F C_{2}$ and $D_{c l}=D_{11}+D_{12} F D_{21}$.

Following the procedure in [14] the complete formulation for the iLMI algorithm can be found, a simplified algorithm for the MIMO PI controller is presented in [7]. To solve the optimization problem, the Yalmip[17] code under Matlab ${ }^{(}$ was used for the LMI formulation, and $\mathrm{SeDuMi}^{1}$ is used as a solver.

Two control structures using the robust iLMI control methodology are presented in this paper. A first structure is proposed, where the measured outputs are the DC bus output voltage and the SC current. In the second structure the FC current is considered as a measured output instead of the $\mathrm{SC}$ current. In the first case, with the measure of the SC current, with a different dynamic form the FC current, the goal of a faster control can be achieved. In the second case, the direct control of the FC current, compared to an appropriate reference signal, could be of interest since it is easy to impose limitations on this current to avoid harmful load transients.

Figure 8 shows the control configuration for the hybrid Fuel Cell/Super-capacitor power generation system of the first proposed structure. The DC bus output voltage reference is fixed at $24 \mathrm{~V}$. The current reference of the $\mathrm{SC}\left(I_{s c}^{*}\right)$, is computed filtering the load current by means of a second order low-pass filter with a cutoff frequency of $1 \mathrm{~Hz}$ and a damping factor of 0.707 . Since the SC dynamic is faster than that of the $\mathrm{FC}$, the performance weight is fixed for a frequency pulsation of $5 \mathrm{rad} / \mathrm{sec}$, for an imposed stabilization time of approximately $t_{s}=0.3 \mathrm{sec}$. The module margins of the sensitivity functions are limited to 2 to gain in robustness. For the control weighting functions, an input duty cycle limit of 0.95 is considered. The proposed methodology is used to compute a multivariable PI controller using the following weighting functions:

$$
\begin{gathered}
W_{\text {perf }_{1}}=\frac{0.2 s+5}{s+0.005} \\
W_{\text {perf } f_{2}}=\frac{0.2 s+0.05}{s+5 \times 10^{-5}} \\
W_{u_{f c}}=\frac{s+15.79}{0.01 s+15.71} \\
W_{u_{s c}}=\frac{s^{2}+3.947 \times 10^{5} s+6.2 \times 10^{6}}{0.01 s^{2}+3.927 \times 10^{5} s+6.169 \times 10^{4}}
\end{gathered}
$$

\footnotetext{
${ }^{1}$ See http://sedumi.ie.lehigh.edu/ (retrieved on June 2010)
}

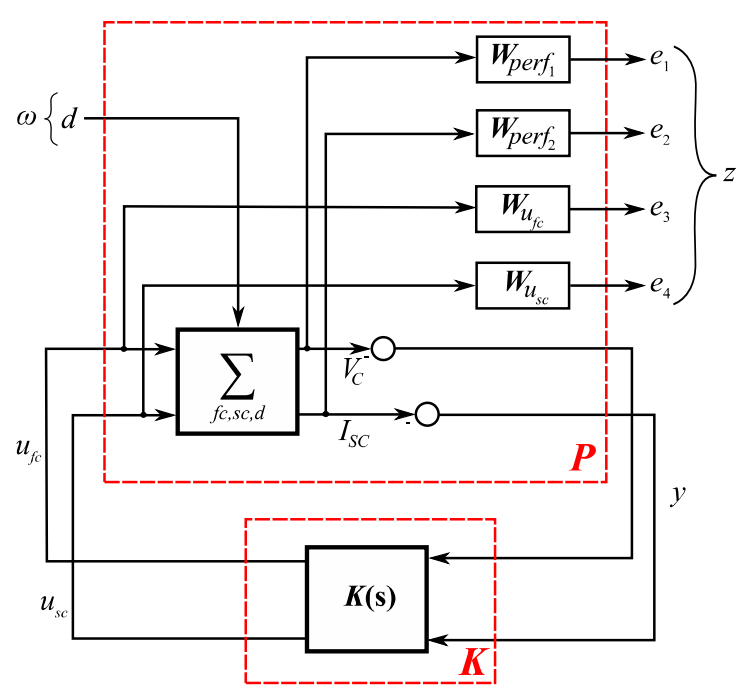

Fig. 8. The first proposed control configuration.

The multivariable PI controller obtained for the first structure is given by:

$$
P I_{i L M I}=\left[\begin{array}{cc}
0.0017+0.3937 / s & 0.0031 / s \\
4.5432+103.0451 / s & 0.5964+22.7415 / s
\end{array}\right]
$$

In the second proposed structure, the FC current is measured instead of the SC current. This structure could be interesting because the FC current is controlled directly. A protective strategy to avoid harmful load transients can be directly applied as a FC current reference. An important number of primary level control strategies are based on imposed reference signals related to the FC dynamic, as the Maximum Power Point Tracker (MPPT), a tracking on the FC efficiency curve, etc. See [4], [18], [19] or even [11] for several examples on primary level control methodologies. A current limitation of $10 \mathrm{~A} / \mathrm{s}$ is fixed for the FC current rate limitation.

The performance weighting functions are redefined as:

$$
W_{\text {perf }}=\frac{0.8 s+1}{s+0.001} \times I_{2}
$$

The performance weighting functions were chosen for a closed loop DC bus output voltage stabilization time of $t_{s}=0.5 \mathrm{sec}$. The convergence of the optimization problem is easily achieved with this second strategy after 4 iterations of the iLMI algorithm. The multivariable PI controller found is given by:

$$
P I_{i L M I}=\left[\begin{array}{cc}
0.0610 / s & 0.0055+0.3217 / s \\
0.0034,+0.0720 / s & 0.0019+0.1292 / s
\end{array}\right]
$$

\section{Simulation Results}

\section{A. First Structure}

The sensitivity functions $\left(S_{1}=V_{C} / d, S_{2}=I_{f c} / d, K_{1} S_{1}=\right.$ $u_{f c} / d$ and $K_{2} S_{2}=u_{s c} / d$ ) are shown in Figures 9 and 10 . The results show how the controller performance is shaped 
using the weighting functions. These results are compared with those obtained with the classic control and a full order (11 states) $\mathcal{H}_{\infty}$ controller synthesized using the same weighting functions.

\section{B. Second Structure}

The sensitivity functions are shown in Figures 11 and 12. The robust controllers presented satisfy the performance weights imposed. The classic PI control structure also respect these weights, however the frequency performance specifications are not considered in the classic control design, in consequence these performances are not handled from the beginning of the design process. Moreover, in the classic control strategy the problem of robustness is not addressed, more attention is given to maintain system stability using the multi-loop method. In the proposed iLMI control methodology, robustness may be considered within the formulation of the LMI in the form of a $\mathcal{H}_{\infty}$ minimization problem.

A time response comparison of the DC bus output voltage for a $50 \%$ load step (10 to $15 \mathrm{~A}$ ) is presented in Figure 13. The non-linear average model was used for time response simulations. Time response results show how a faster load disturbance rejection is obtained with the first proposed structure. However, for practical implementation, a control strategy with direct access to the FC current is desirable for safety. The evolution of the system currents for the two proposed strategies is presented in Figures 14 and 15. The advantage of a direct control of the FC current becomes evident with these dynamics as a limitation of the FC current rate is easily achieved with the second proposed structure. For this reason the second structure is retained for implementation on the real-time testbench. An important advantage of the proposed methodology is the improvement in the control system robustness, as it was already proved using a complete $\mu$-analysis for the same type of system in [7].

\section{EXPERIMENTAL RESULTS}

\section{A. Fuel Cell Emulation}

The test-bench used for validation was designed for a real $1 \mathrm{~kW}$ PEMFC. To avoid harmful operational conditions in the real FC stack during the load transients tests for control validation, an emulator of the FC dynamic was implemented. A Xantrex ${ }^{(\mathcal{1}} 100-60$ DC programmable source and a Simulink/dSPACE real-time environment was used for the emulator. The source is prepared under the remote voltage control mode and is controlled through a $0-10 \mathrm{~V}$ signal. The real measured polarization curve of the $\mathrm{FC}$ is used for static modeling. The dynamic model of the FC presented in Figure 1 is used. The emulator is validated using load steps from a pure resistance load obtained under the "Resistance Mode" of a TDI RBL488 electronic load. The validation results obtained for load steps of $25 \%(0-10 \mathrm{~A})$ and $100 \%(0-35 \mathrm{~A})$ are presented in Figures 16 and 17 respectively. These results are validated by comparison to the results obtained with computer simulation of the open loop system (no control).

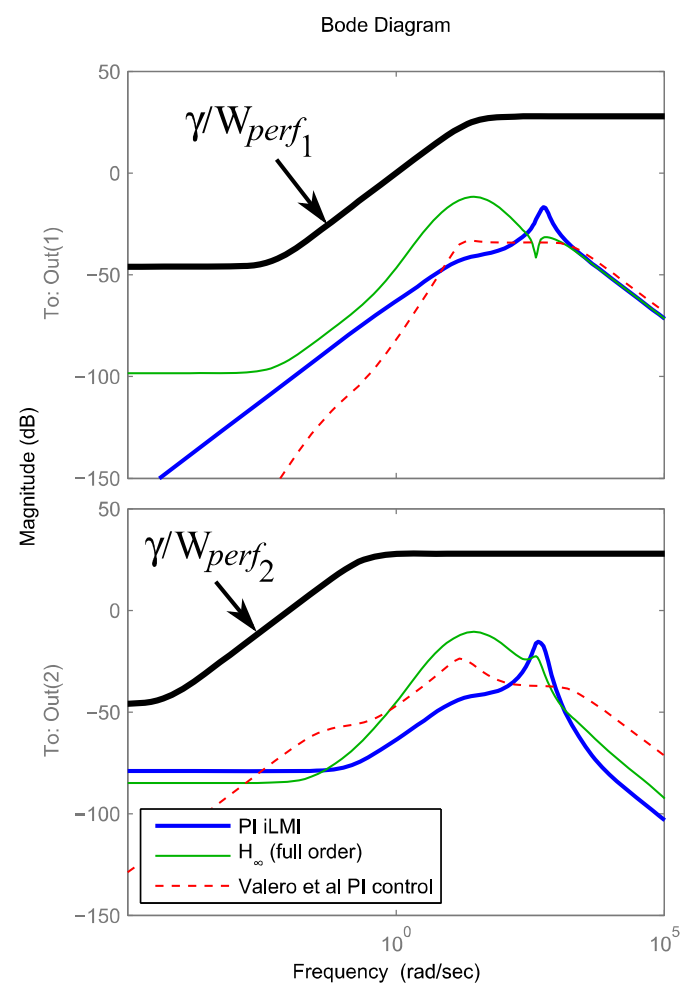

Fig. 9. Sensitivity function $\left(S_{1}\right.$ and $\left.S_{2}\right)$ trace for the first proposed strategy.

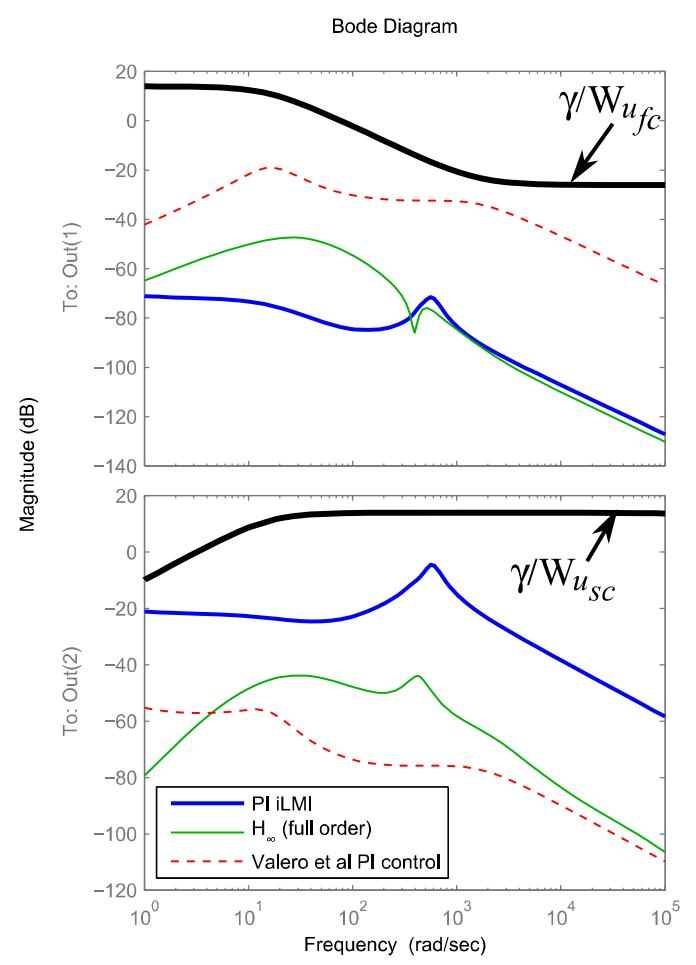

Fig. 10. Sensitivity function $\left(K_{1} S_{1}\right.$ and $\left.K_{2} S_{2}\right)$ trace for the first proposed strategy. 


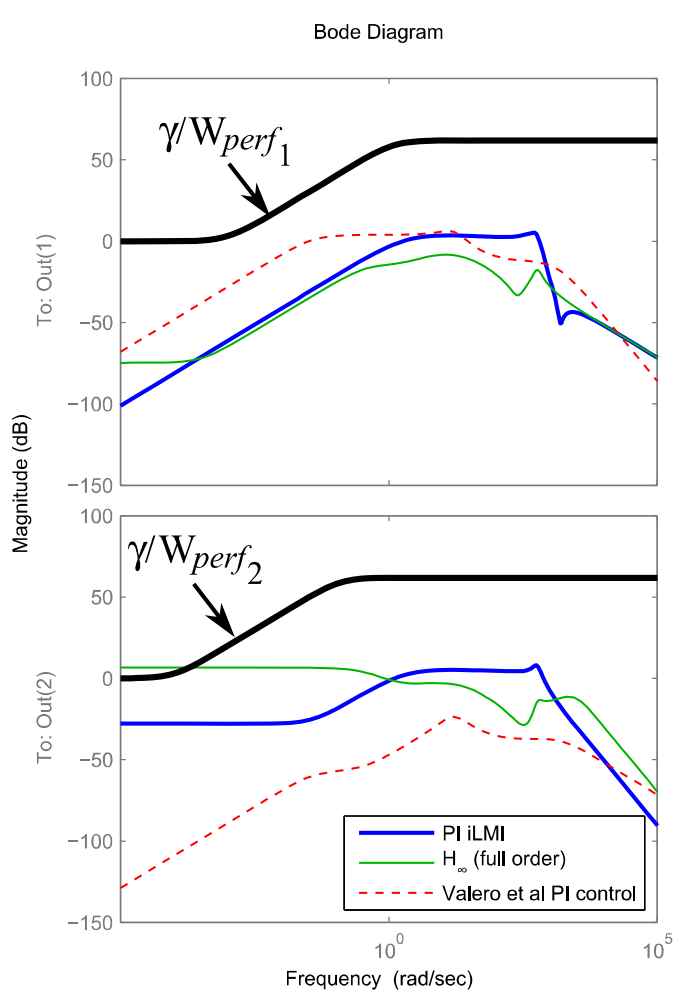

Fig. 11. Sensitivity function $\left(S_{1}\right.$ and $\left.S_{2}\right)$ trace for the second proposed strategy.

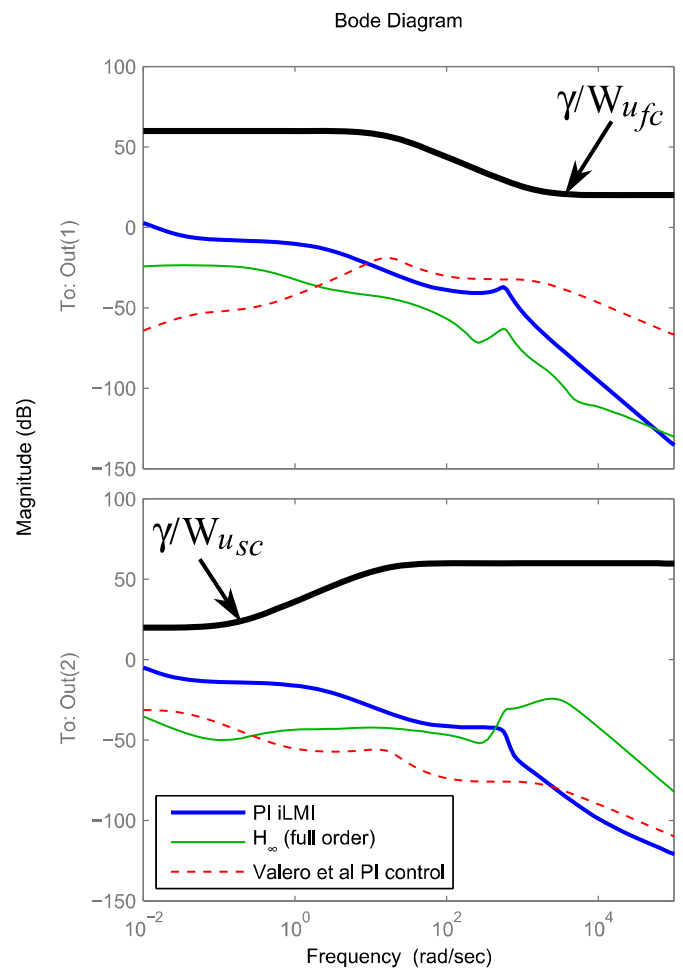

Fig. 12. Sensitivity function $\left(K_{1} S_{1}\right.$ and $\left.K_{2} S_{2}\right)$ trace for the second proposed strategy.

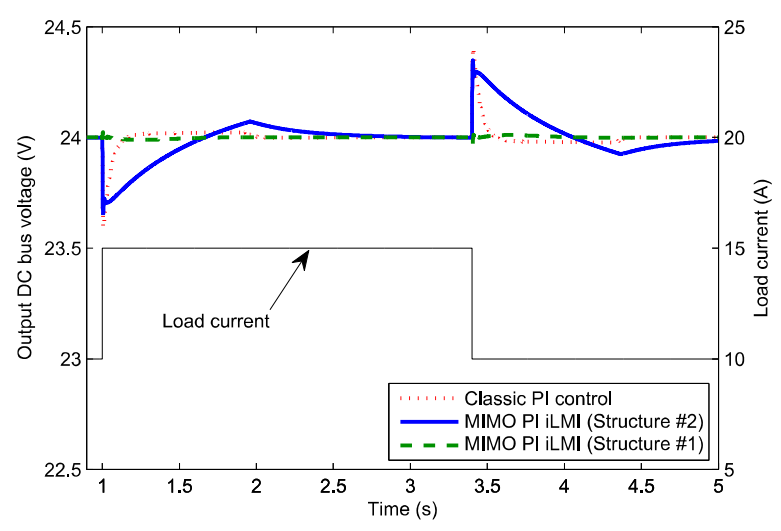

Fig. 13. Time domain response of the different closed loop systems (output voltage).

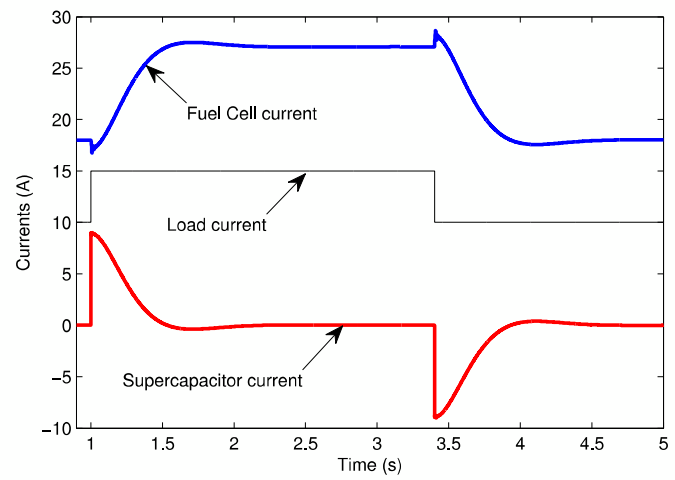

Fig. 14. Time domain response of the different closed loop systems (system currents with the first proposed structure.

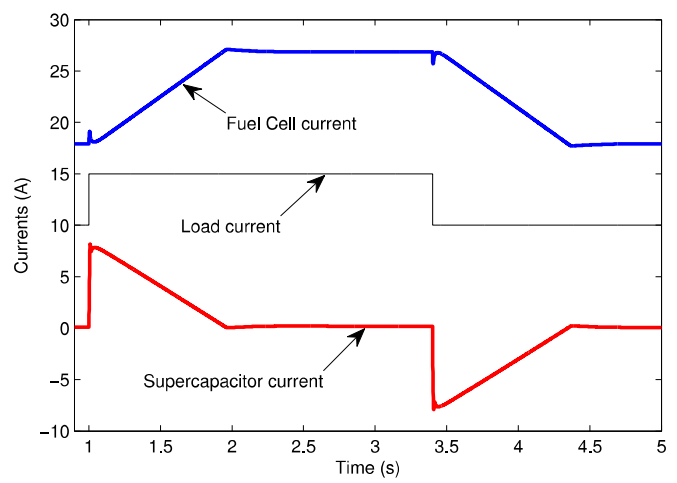

Fig. 15. Time response of the different controllers (system currents with the second proposed structure).

The 1kW PEMFC chosen has fast dynamics, voltage response to a load step is around $10 \mathrm{msec}$. Due to the DC programmable source limitations and the inherent electronic load dynamics, a voltage overshoot is observed in Figure 17. However, this should not be a problem since for closed-loop control validation dynamics are around $0.5 \mathrm{sec}$. Moreover, load steps for control validation will be limited to a $50 \%$ maximum. 


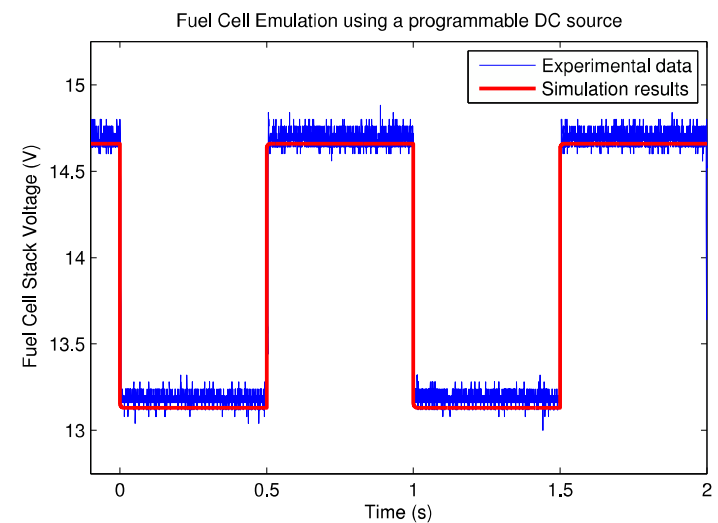

Fig. 16. FC emulator validation $(0-10 \mathrm{~A}$ step).

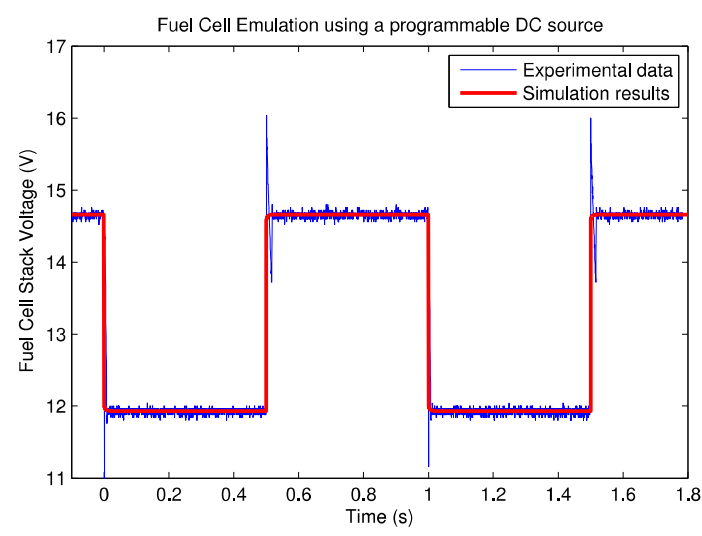

Fig. 17. FC emulator validation $(0-35 \mathrm{~A}$ step $)$

\section{B. Hybrid System Real-Time Experimental Results}

The MIMO PI iLMI control is implemented in the testbench and the emulator system described before. Implementation results are presented in Figures 18 and 19 for the first proposed strategy. The results are shown for a $50 \%$ load step from 10 to $15 \mathrm{~A}$.

The results obtained are promising, several comments are possible. The output DC bus voltage is properly regulated within a $\pm 10 \%$ variation limit. The voltage drop is still high $(2.9 \mathrm{~V})$ and slightly different from that obtained using the average model simulation (Fig. 13), this is probably due to high system losses in the power wiring. Despite this, a better regulation is obtained with the proposed strategy when compared to the simulation result obtained with the classic control (Figure 13). In the time domain simulation a faster disturbance rejection is obtained with the classic PI control, however a better robustness for the proposed methodology has already been proven in [7]. Furthermore, within the proposed methodology shown in figure 6 , the use of the $\mathcal{H}_{\infty}$ framework aims toward a systematic control approach. The FC current rate limitation is efficiently implemented (see channel 3 in Figure 19), protecting the FC from harmful load transients. Finally, a smooth transient behavior in the FC current leads to

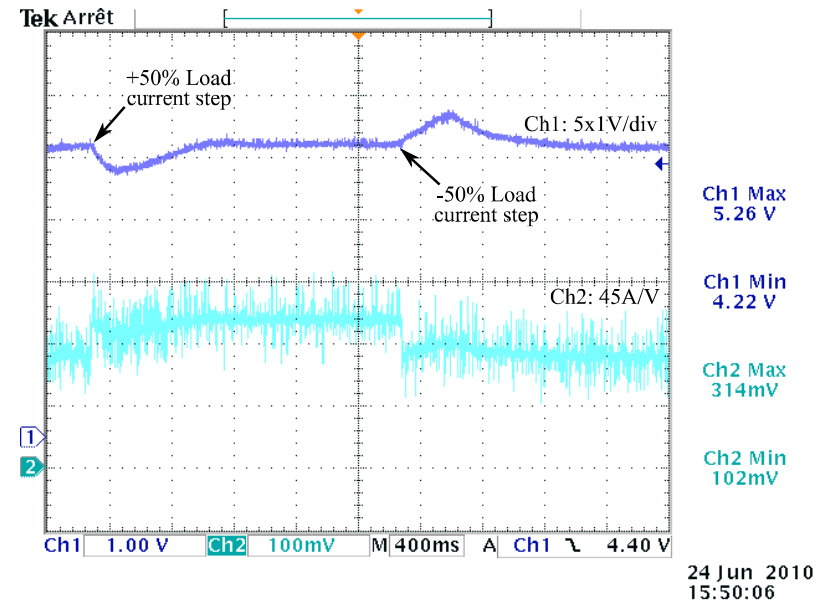

Fig. 18. Implementation Results. Ch1 is the output DC bus voltage and $\mathrm{Ch} 2$ is the load current.

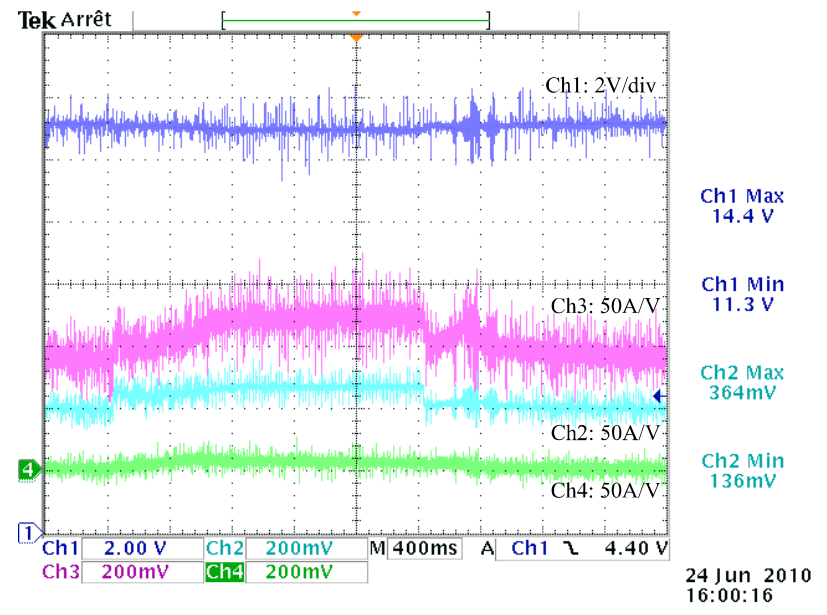

Fig. 19. Implementation Results (system currents). Ch1 is the FC voltage, $\mathrm{Ch} 2$ is the load current, $\mathrm{Ch} 3$ is the FC current and Ch4 is the super-capacitor current.

a small drop in the FC stack voltage (see channel 1 in Figure 19).

\section{CONCLUSION}

A robust methodology for multivariable PI control design has been proposed. This approach aims toward a generalized systematic methodology where control synthesis is straightforward. Time/frequency and robust performance is adjusted using weighting functions. The proposed methodology focus on robust control, for this, a complete robustness analysis is a critical part of the strategy. The robustness of the methodology was proved in previous works. Simulation and real-time implementation results shows the effectiveness of the proposed methodology on disturbance rejection and, especially, on protecting the FC from harmful current transients. For future works, the validation of the controller robustness is envisaged using real-time experimental results. 


\section{REFERENCES}

[1] M. W. Ellis, M. R. V. Spakovsky, and D. J. Nelson, "Fuel cells systems: Efficient, flexible energy conversion for the 21 st century," Proc. of The IEEE, vol. 89, pp. 1808-1818, Dec. 2001.

[2] C. Wang and M. H. Nehrir, "Load transient mitigation for standalone fuel cell generation systems," IEEE Trans. on Energy Conversion, vol. 22, pp. 864-872, Dec. 2007.

[3] S. Basu, Recent Trends in Fuel Cell Science and Technology. New York, USA: Springer-Anamaya, 2007

[4] Y. S. Han, S. Li, X. Park, S. Jeong, H. Jung, and B. Jung, "A power control scheme to improve the performance of a fuel cell hybrid power source for residential application," in Power Electronics Specialists Conference, 2007. PESC 2007. IEEE, June 2007, pp. 1261 - 1266.

[5] O. Erdinc, B. Vural, M. Uzunoglu, and Y. Ates, "Modeling and analysis of an fc/uc hybrid vehicular power system using a wavelet-fuzzy logic based load sharing and control algorithm," International Journal of Hydrogen Energy, vol. 34, no. 12, pp. 5223 - 5233, 2009.

[6] J. Nolan and J. Kolodziej, "Modeling of an automotive fuel cell thermal system," in Journal of Power Sources, vol. 195, no. 15, 2010, pp. 4743 -4752 .

[7] D. Hernandez-Torres, D. Riu, O. Sename, and F. Druart, "On the robust control of DC-DC converters: Application to a hybrid power generation system," in 4th IFAC Symposium on System, Structure and Control (Accepted for publication), Sep. 2010.

[8] S. Sailler, F. Druart, D. Riu, and P. Ozil, "Simulation of a PEMFC-super capacitor hybrid system," in 18th European Symposium on Computer Aided Process Engineering ESCAPE 18, 2008

[9] S. Buller, E. Karden, D. Kok, and R. de Doncker, "Modeling the dynamic behaviour of supercapcitors using impedance spectroscopy," IEEE Trans. on Industry Applications, vol. 38, no. 6, pp. 1622-1626, November/December 2002.
[10] R. D. Middlebrook, "Topics in multiple-loop regulators and currentmode programming," Power Electronics, IEEE Transactions on, vol. PE2, no. 2, pp. 109-124, April 1987

[11] I. Valero, S. Bacha, and E. Rulliere, "Comparison of energy management controls for fuel cell applications," Journal of Power Sources, vol. 156, no. 1, pp. 50-56, 2006, selected papers from the 2nd France-Deutschland Fuel Cell Conference.

[12] P. Petitclair, S. Bacha, and J. P. Rognon, "Averaged modeling and nonlinear control of an asvc advanced static var compensator," $27^{\text {th }}$ Annual IEEE Power Electronics Specialists Conference, pp. 753-758, 1996.

[13] S. Skogestad and I. Postlethwaite, Multivariable Feedback Control: Analysis and Design. New York, USA: Jhon Wiley \& Sons, 1996.

[14] Y. He and Q.-G. Wang, "An improved ilmi method for static output feedback control with application to multivariable pid control," IEEE Trans. on Automatic Control, vol. 51, pp. 1678-1683, Oct. 2006.

[15] D. Hernández-Torres, M. Sautreuil, N. Retière, D. Riu, and O. Sename, "A new methodology for aircraft hvdc power systems design," Industrial Technology, 2009. ICIT 2009. IEEE Int. Conf. on, pp. 1-6, Feb. 2009.

[16] F. Zheng, Q. G. Wang, and T. H. Lee, "On the design of multivariable PID controllers via LMI approach," Automatica, vol. 38, pp. 517-526, March 2002

[17] J. Löfberg, "YALMIP: A toolbox for modeling and optimization in MATLAB," in Proceedings of the CACSD Conference, Taipei, Taiwan, 2004. [Online]. Available: http://users.isy.liu.se/johanl/yalmip

[18] P. Thounthong and S. Rael, "The benefits of hybridization," Industrial Electronics Magazine, IEEE, vol. 3, no. 3, pp. 25-37, Sept. 2009.

[19] K.-W. Suh and A. G. Stefanopoulou, "Coordination of converter and fuel cell controllers," International Journal of Energy Research, vol. 29, no. 12, pp. 1167-1189, 2005. 